\title{
The Ethics of the Ecology of Fear against the Nonspeciesist Paradigm: A Shift in the Aims of Intervention in Nature
}

\author{
Oscar Horta \\ Fundación Española para la Ciencia y la Tecnología \\ Visiting Scholar Department of Philosophy \\ Rutgers University \\ ohorta@dilemata.net
}

\begin{abstract}
Humans often intervene in the wild for anthropocentric or environmental reasons. An example of such interventions is the reintroduction of wolves in places where they no longer live in order to create what has been called an "ecology of fear", which is being currently discussed in places such as Scotland. In the first part of this paper I discuss the reasons for this measure and argue that they are not compatible with a nonspeciesist approach. Then, I claim that if we abandon a speciesist viewpoint we should change completely the way in which we should intervene in nature. Rather than intervening for environmental or anthropocentric reasons, we should do it in order to reduce the harms that nonhuman animals suffer. This conflicts significantly with some fundamental environmental ideals whose defence is not compatible with the consideration of the interests of nonhuman animals.
\end{abstract}

\section{Introduction}

Humans intervene continuously in the wild. There are several reasons why they do so. In most cases, they do it just for the sake of clearly recognizable human benefits (as when they transform some environment to make it more comfortable and less risky for humans to inhabit or visit). In other cases, they intervene in order to maintain certain patterns of environmental balance. They often do the latter because it is in their own interest. The motives for this can be variable: the promotion of tourism, an interest in getting some resources present in the area in which the intervention takes place, scientific, cultural or aesthetical reasons... In other cases, though, they do it, allegedly, just for its own sake. The assumption then is that there is a certain value in the preservation of such balance, reflected in Aldo Leopold's well known dictum "[a] thing is right when it tends 
to preserve the integrity, stability, and beauty of the biotic community. It is wrong when it tends otherwise" (Leopold 1966, 262).

In spite of this, humans very rarely intervene in nature for the sake of the interests of other sentient beings, that is, nonhuman animals. Moreover, the kinds of intervention they carry out are often harmful for them. In fact, if such harm is ever considered, it is only insofar as it is instrumentally relevant for the ends that are being aimed at. The reduction of the harms animals suffer, per se, is not considered a goal that should be pursued when these kinds of interventions in nature take place.

In this paper I will evaluate the reasons we may have to support the ends that different interventions aim to achieve. To carry out such analysis, I will begin with a particular intervention of this kind: the reintroduction of wolves. This measure has been considered in recent years in places such as the Scottish Highlands (see for instance Watson Feathersome 1997; Nilsen et al. 2007; Wilson 2004; Manning et al. 2009; as well as BBC News 1999; 2000 and 2008; Morgan 2007; or O'Connell 2008 for media coverage of the issue). And it was implemented before in places such as Yellowstone National Park, in the United States. This is a measure that would be harmful for a number of animals but has been considered in order to stop certain changes in the Highlands environment, through the imposition on ungulates of what has been called an "ecology of fear" (Ripple and Beschta 2004). Such a measure has been much discussed, but not because of the consequences it would have for nonhuman animals, but rather because of the way it could affect some human (non-vital) interests.

However, in dealing with this question I do not intend to restrict my analysis to this particular intervention, nor to this type of intervention. Rather, I will consider it as an example to examine the more general question of what should be the ends we should aim for when we intervene in nature. 
I want to say in advance that I do not intend to make a technical case here as regards whether the particular intervention I will tackle might achieve its goals or not. Nor will I try to assess any other alternative ways in which such ends could be pursued. On the contrary, I will try to examine the ethics underlying the acceptance of those ends. I will consider the question of whether it is right to harm animals in order to achieve such ends. I will then consider the reasons we may have to intervene in nature for the sake of a completely different purpose, which is to reduce the harms animals suffer. I will argue that this is something we should aim for even if it strongly conflicted with what environmentalists may regard as valuable.

This means that the position I will defend here should not be confused with a criticism of intervention in nature per se. My conclusion will be that we are not justified in intervening in nature when doing so generates more harm for nonhuman animals. But I will also claim that others interventions should be carried out.

To defend this, I will proceed as follows. First, in section 2, I will explain the reasons why environmentalists defend the reintroduction of wolves and the ways it would be harmful for a number of animals. Then, in section 3, I will claim that in proposing such a measure they are considering the interests nonhuman animals have in a way that is completely different from that in which they would consider human interests. In section $4 \mathrm{I}$ will argue that treating nonhuman animals comparatively worse than humans in cases in which their interests are equally important for each of them is unjustified. I will claim that it is a form of speciesism. In light of this, in section 5 , I will argue that this presents a serious objection to the way in which the interests of animals are considered in cases such as the aforementioned. I will claim that their supporters assume a speciesist viewpoint. Next, in section 6 , I will consider the claim that an intervention such as this one could be actually good for nonhuman animals even if we would never carry it out if humans were affected. I will argue that the issue has not been really researched and that there are reasons to doubt 
this claim. Then, in section 7 , I will consider the claim that without apex predators herbivores will end up disappearing from places such as the Highlands. And in section 8 I will claim that this argument is inconsistent with the practice of farming. After that, in section 9, I consider some potential consequences for other animals due to the trophic cascade that the reintroduction of wolves might produce. In section 10 I will introduce another argument by pointing out that there are strong reasons to doubt our common assumptions regarding the aggregate wellbeing of animals. I will consider some facts regarding this that have been presented by Yew-Kwang Ng and Alan Dawrst, which may lead us to conclude that the suffering of nonhuman animals outweighs their wellbeing. Then, in section 11, I will consider whether we may have other reasons to think that this intervention brings about a positive outcome. This might be so according to a biocentric or an environmental holistic viewpoint. I will claim that none of these views can be considered compelling ones. Next, in section 12, I will claim that none of this drives us to reject intervention in nature. Rather, I will argue that it gives us strong reasons to intervene for the sake of the reduction of the harms nonhuman animals suffer. Finally, section 13 concludes.

\section{The Ecology of Fear: The Effects of Wolf Reintroduction on Elk and Deer}

Reintroduction of wolves is often advocated because it is seen as something good in itself (see for instance Mech 1995). It is often believed that restoring ecosystems previously existing is something environmentally valuable (for a criticism of this view, see Shelton 2004). However, there are other reasons why their reintroduction has been defended. In the Scottish Highlands this measure has been debated recently on the claim that the red deer population has grown too much and is causing significant damage to the local vegetation by grazing.

It has been claimed that the reintroduction of wolves would reverse this process. This claim is based on conclusions drawn from what happened in Yellowstone National Park in the USA in the last 
decades, where wolf reintroduction was carried out in 1995 and 1996. The last wolves originally living in this park in Yellowstone had been killed by 1926 . However, after much debate, seventy years later 31 Mackenzie Valley wolves taken from Canada were brought to the park. Since then, their numbers have grown up to 124 in 2008 (Smith et al. 2009). Many people find it aesthetic to have wolves back in Yellowstone, and this was one of the reasons why they were reintroduced. But this measure was also carried out in an attempt to restore the trophic chain preexisting the elimination of wolves in the park some decades earlier. The reason for this was that, in the absence of wolves, elk were free to move around in the park and flourish, even though for decades humans hunted them in huge numbers. And it was been argued that they were "overgrazing" some of the park areas. This claim was seriously disputed (Yellowstone National Park, National Park Service 2009). But, environmentalists were nevertheless worried about this because elk were grazing one particular plant. They were eating the young aspen shoots before they grew up, so these trees were not reproducing. For this reason, after much discussion, reintroducing the wolves was assumed to be the only reliable way to stop this process.

What are the grounds for this? How can wolves prevent ungulates from eating the tree shoots? Of course, one way is by killing them and thus reducing their number-it is estimated that around 22 elk per wolf are killed each year in the park (White et al. 2005, 36), and that since wolf reintroduction, the northern Yellowstone elk herd has declined by around 50\% or more (Smith 2005, 23; White et al. 2005, 35-36). However, the key factor here is something else. It is fear. If wolves are around, their potential victims fear grazing in open meadows, since these are places in which wolves can see them much more easily. So they have to hide in the woods and get their food from bushes and low tree branches (see Ripple and Larsen 2000; Ripple and Beschta 2007; see also Preisser et al. 2005). That is the reason why the resultant biotic relations that arise from this have received the name "ecology of fear". And the landscape resulting from this, in which even though there are herbivores living in the area they do not 
graze in open fields, has been called "landscape of fear" (Laundre, J. W. et al. 2010).

Now, the way in which herbivores are harmed by this seems clear. The harm that is inflicted on them is not reduced to their killing, but includes their suffering as well. Fear can be an extremely distressing feeling. And this is not the only way in which they are harmed by the reintroduction of wolves. They also get poorer nourishment as a result of it. This, again, has been observed in Yellowstone: because the elk no longer dare to feed out of the woods, their nutrition had been notably worse since the arrival of the wolves (Christianson and Creel 2010). (In fact, this was, together with the killings, one reason why their population declined. Elk are weaker and more liable to die for other reasons, and they have less offspring [Creel et al. 2009]). We can thus conclude that this kind of measure imposes significant harm on the herbivores who are subjected to an ecology of fear. We could also assume that, on the other hand, this measure benefits wolves. But this would be a controversial claim. Reintroductions do not benefit the actual wolves that are captured, transported and released into an unknown environment. They would be better off if they were left alone in the places they came from (unless they were starving there, or being harmed in some other way). We could nevertheless say that the measure would benefit those wolves who would exist in the future. To make this claim, however, we need to assume an impersonal conception of the good according to which we are benefiting future beings by making it possible that they would exist (a view that entails, for instance, that if we do not have children we are failing to do something good-at least in some respect-for some potential beings). This is a very controversial claim. At any rate, considering the numbers of ungulates and wolves involved (recall that an average of 22 elk per wolf were killed each year in Yellowstone), it seems clear that even if we accept this claim we will still have to conclude that the harm the measure imposes on some animals clearly overshadows the benefits it may bring to others. 


\section{A Clearly Different Consideration of Interests}

The reintroduction of wolves is never met without significant controversy. Many people strongly oppose it. But the arguments for this do not have to do with the interests of nonhuman animals. Farmers of neighboring areas are some of those who most strongly object to the reintroduction of wolves. They complain that the wolves might kill some of the animals they keep on their property. Of course, their concern is not the good of these animals (after all, they are being raised to be eventually sent by the farmers themselves to be killed). Rather, it is clear that the interest that the farmers have in not having the wolves around is an economic interest. Together with them, hunters often oppose these measures, in order to have more ungulates available for them to hunt. (Alleged concern for wolf attacks on humans is also sometimes expressed as a reason against their reintroduction. However, these attacks are so extremely rare that this seems to be an argument that is simply used by those who oppose the presence of wolves for the other reasons mentioned above, rather than something that may actually be of concern to them).

Now, if we compare the weight of the different interests involved there is an obvious contrast. An interest in not gaining some more money or in getting some entertainment in killing animals is clearly less significant than an interest in not losing one's life (either by the action of a wolf or by a human hunter). And it is also inferior to an interest in not being subjected to continuous fear and in not being forced to be malnourished. However, the former can be crucial in stopping these measures from being carried out, while the latter are not given any consideration whatsoever. Complaints by farmers and hunters are usually taken seriously, while concern for the wellbeing of nonhuman animals is not even regarded as a serious concern. How can this be? The answer is obvious. The different interests involved in the issue are not being considered according to the weight they actually have for those who possess them. Rather, they are assessed in accordance to whether or not they are possessed by humans. It is 
clear that if humans, rather than ungulates, were killed and caused to suffer, reintroduction of wolves would not be even discussed. This entails that at least one of the following statements is right:

a. Wolf reintroduction would be a good measure even if a number of humans were killed, terrified and starved due to it.

b. Wolf reintroduction may be considered unacceptable because of the ways in which it harms the animals they hunt.

c. The interests of humans and nonhumans have to be considered in completely different ways.

For most people, (a) cannot be considered acceptable. This includes those theorists who have defended what has been called the land ethic and other environmentalist viewpoints (see for instance Callicott 1990, 103; 2000, 211). If we grant this to be right, we are left with the question of whether it is (b) or (c) we must accept. In order to examine this, I will now consider whether claim (c) can be justified.

\section{Questioning Anthropocentric Speciesism}

The view that humans' interests must be taken into account in ways in which nonhumans' ones need not be considered has been put forward in several different ways. Its defenses can be grouped into five general categories. First of all, this idea is often taken for granted, or assumed to be right by mere definition. It is claimed that it should be obvious that humans' interests should count for more than nonhumans' ones. This view offers no argument in support of the claim it is defending.

But there are other ways in which this perspective can be defended. For instance, it is sometimes claimed that we should assume it because humans have an ontological status higher than that of other animals, or because humans are God's chosen species (see Aristotle 1998, 1254a-1256b; Reichmann 2000). These claims appeal to intrinsic features or to relations whose existence cannot be verified, nor falsified by any means. There is no way in which we may 
verify that all humans and no other animal have these features or relations, because there is no way in which we can test whether anyone at all can have them. In this way, these claims are similar to definitional ones. They just assume in some way that humans have some sort of privileged status, which is what they would need to prove. So they fail to justify the idea that human interests are morally more important than nonhumans are.

But, apart from these ones, there are other ways in which the predominance of human interests has been defended. It has been also claimed that humans have certain features (consisting, basically, of certain intellectual capacities), which no nonhuman animal possesses. And it has been maintained that those features are the ones that should determine that someone must be morally considered (see, for instance, Descartes 1932; or, in more recent times, Carruthers 1992). Besides, it has been argued in other cases that humans have some special relations of solidarity, sympathy or power in which nonhuman animals are not engaged, and that it is this that determines whether or not we should morally consider them (see, for instance, Whewell 1852, 223).

However, as many of those who have worked in animal ethics have pointed out, these arguments fail to draw a line separating humans from nonhumans. There are many humans such as infants and those with cognitive disabilities who lack the mentioned intellectual capacities. And there are also humans who are alone and powerless, and thus fail to have the relations considered to be relevant according to these arguments. This means that if we want to defend the moral consideration of all human beings, we cannot assume the moral relevance of criteria that exclude nonhumans.

This argument may drive us to reject the idea that these criteria are morally relevant, something which we may also conclude by means of a different argument, if we consider what follows. Having certain capacities or relations is something that can make us liable to be harmed or benefited in certain ways. But it is not what determines that we can be harmed or benefited as such. This is determined, 
rather, by the fact that we are sentient beings, who can have positive and negative experiences. Hence, if we want to make our decisions according to what can be good or bad for those who may be affected by them, we need to consider what is relevant for them to be harmed or benefited. If we accept this argument based on an appeal to relevance, we will reject any criteria for moral consideration which differs from sentiency.

Hence, I conclude that all the defenses of the predominance of human interests fail, so we cannot consider this view to be justified. If this is right, we must conclude that such a position is a form of speciesist discrimination.

\section{A Speciesist Policy}

In line with this, we have to conclude that it is unjustified to assume that the reintroduction of wolves, which has been discussed in Scotland, is acceptable because the individuals who would be harmed by it would be nonhuman animals and not humans. Those who defend such a measure are not considering equally the weight of the interests of humans and nonhuman animals. Rather, they assume a speciesist position according to which they are prepared to sacrifice the interests of nonhuman animals for purposes for which they would not sacrifice less significant interests of nonhumans. This has to be concluded regardless of whether we agree with this measure or not. For even if we thought it would be correct to sacrifice the elk for the sake of aspens and other trees, or for further consequences to be expected from the conservation of these plants, we might avoid speciesism if we also agreed to sacrifice humans for that sake. However, the latter is never the case. Most people would reject such a view when it comes to human beings. Although there are some theorists who have defended it, such as Linkola (2009), who supports massive killings of human beings and similar measures for the sake of the environment, their positions are widely repudiated. Their opinions been rejected by most environmental theorists, who assume anthropocentric positions-even if they combine them with an environmental holist or biocentrist perspective (see for instance Næss 
2005, 98; Callicott 1989; Norton 1987, 13; Varner 1998, 79; or Hargrove 1992). Moreover, it is also apparent that proposals involving mass killings of human beings have not been influential either in devising the guidelines according to which nature is policed today.

\section{Is Reintroduction of Wolves Good for Other Animals?}

It could be claimed that even if the reintroduction of wolves were a speciesist measure, it could still be one we should support, because it would be good for nonhuman animals. There is something rather odd with this assumption, because those who would reject applying such a measure would do so out of their concern for humans themselves. If they thought the measure was good for those involved, they would have no problem with applying it if all the nonhuman animals affected by the measure, for good or bad, were humans. At any rate, this is not completely conclusive, because it may just happen that the conception of the good of those who would oppose this measure if humans were involved were wrong.

Hence, in order to deal adequately with this problem we need to examine whether we have reasons to claim that the benefits that some individuals would get if this intervention took place would outweigh the harms that others would suffer. It could be assumed that in light of the different studies that have been carried out in support of this measure we should not doubt the many benefits it could bring about for animals as individuals living in an ecosystem which appears to be enriched by it. However, such studies have pointed out the effect it could have in maintaining a certain balance in the environment or in stimulating biodiversity. Yet this in no way amounts to a clear examination of the problem of whether such effects would imply a higher level of aggregate wellbeing for the animals involved. Nor does it really give an answer, in particular, to the question of whether the introduction of the wolves would cause a boost in the levels of wellbeing present in the ecosystem enough to outweigh the impact in terms of the suffering and deprivation of 
wellbeing inflicted on deer and other animals. In fact, it is very revealing that this question has not really been tackled as such by those studies dealing with the consequences of the introduction of wolves. The reason is, obviously, that this is not even considered to be an issue.

This lack of research means that the case has not been established that animal wellbeing would be increased, rather than reduced, by this measure. Anyway, it could be claimed that this would be obvious considering some facts that have been empirically studied that appear to be relevant for the wellbeing of nonhuman animals. I will assess now some reasons that could be pointed out to defend this view.

\section{Future Effects on Herbivores}

One argument that could be considered here was presented by Aldo Leopold (1966 139-140, 268) some decades ago. He claimed that after the extermination of wolves in many states in the USA, deer reproduced in high numbers there, until they ate all the food available and, finally, disappeared. Allegedly, this would have a terrible impact on the wellbeing of herbivores that could be avoided by predators. This claim, however, is far from being clear.

One could consider that Leopold is referring here to the effects of the elimination of predators, rather than to their reintroduction. Note also that his observations took place in recent decades, while in a place such as Scotland the last wolves were killed in the 17th or 18th century. Consider also that even in a place such as Yellowstone, in which the wolves were finally reintroduced, the measure was implemented for the impact of elk on some particular plant species, not because they were actually "overgrazing" the park (as I pointed out above, some studies showed that this was not happening). Anyhow, this is not the main point. More important than that is the fact that Leopold's concern here was not really with animal wellbeing, but with the conservation of a certain ecosystem. Thus, even if deer grazing ended up having the effect he describes, it is not clear at all 
that this would entail more harm than the continuous infliction of an ecology of fear on a whole community of deer. At some point, the aggregate number of animals harmed and killed by this measure would be much higher than the number of animals who would die due to lack of food-consider also here something that was already pointed out above: when food becomes scarce ungulates have less progeny, which reduces the number of individuals actually suffer from hunger.

Apart from this, there is something else going on in the case of the reintroduction of wolves in Scotland that shows a clear inconsistency in its rationale. We will see it now.

\section{An Argument Inconsistent with Farming}

Supporters of wolf reintroduction have claimed that though on the one hand it is understandable that farmers fear that wolves would kill some of the animals they keep as their property, on the other hand they should also welcome one consequence the reintroduction would have, that is, that there would be less deer to compete with grazing animals such as sheep. Furthermore, one of the reasons presented to favor the reintroduction of wolves is that deer compete with sheep for food (Clutton-Brock et al. 2004; Nilsen et al. 2007). From a nonspeciesist viewpoint that considers the interests of the sheep this is morally objectionable (because sheep farming would be seen as unacceptable in the first place). But there is something more to say here.

If there were a true concern for the impact on the vegetation of the presence of deer, eliminating sheep farming would be the first measure to introduce. Sheep are grazers and their impact on the local vegetation is similar to that which is considered to be negative when deer cause it. It is obvious that farming has the same effects that the reintroduction of wolves is intended to deal with, without it being considered to be catastrophic by defenders of wolf reintroduction. The obvious reason for this is that humans benefit from the exploitation of sheep. 
Moreover, wolves kill many animals kept by humans for their exploitation. For instance, it has been estimated that in those areas of Spain where wolves live, they cause an $80 \%$ of sheep mortality for what are considered to be "natural causes" (Blanco 2000)-that is, for those deaths that take place before humans themselves kill the sheep-. Yet the fact that wolves kill sheep is not considered to be a reason for their reintroduction, but a reason against it. The fact that wolves kill animals is seen as something positive if they are animals from whose exploitation humans do not profit. Otherwise, it is seen as negative, regardless of the fact that the impact on the vegetation of all these animals is basically the same. This is also what explains that hunters see the fact that wolves reduce the population of some ungulates as negative: because they see these animals, as farmers see sheep, as animals available for them to use (as "game" to be hunted).

What is more, as Nilsen $(2007,1000)$ points out, and one can discover easily by taking a look at the official records on the issue (Scottish Government Rural and Environment Research and Analysis Directorate 2010), sheep farming is maintained in Scotland basically thanks to subsidies. Otherwise it would be hardly a profitable activity. If we consider the interests of the deer, this presents the reintroduction of wolves as a cynical measure.

It could be claimed that there is a difference between the impact that sheep and deer cause, which is that deer graze in what are considered to be more or less "wild" areas, while sheep graze in places that are closer to where humans live or that have been more affected by human action. But this is not a good argument. Firstly, as a matter of fact this is often not so. Secondly, this assumes a questionable distinction between those areas of lands that are regarded to be more and less worthy of conservation in a certain state. The reason why this distinction is questionable is that it is based on considerations that have to do with human action. Some areas are considered to be more valuable because humans have had a lesser impact so far on them, because they are not privately owned, for aesthetical reasons, etc. But none of this means necessarily that 
the conservation of their environmental value could have an effect upon the wellbeing of animals different from that which would be brought about if the measure affected other areas.

\section{Trophic Cascade Effects}

Apart from the argument we have just considered, there is another way in which we could believe that this intervention could raise the aggregate wellbeing of nonhumans. Perhaps this could happen through some more or less complex alterations in the trophic chain. Of course, if we only consider wolves and the animals they hunt, the reintroduction of wolves has a clearly negative impact in terms of animal wellbeing. But this measure may have many others consequences. For instance, it has been observed that the disappearance of wolves in the USA has led to an increase in the population of mesopredators such as coyotes, which has meant that some of the animals they hunt, such as pronghorn antelopes, have been killed in higher numbers (see Prugh 2009). And far more complex trophic relations may be altered by whether there are wolves around or not. For sure, if this entailed less total suffering for wild animals we would have strong reasons to support this measure. However, such complex effects remain yet to be investigated in enough detail. Things could be the other way around. We lack an understanding of the whole ramifications, for good or bad, upon the wellbeing of nonhuman animals of the introduction of an ecology of fear. However, we are certain of the harm imposed on the victims of it. This gives us a pro tanto reason to reject such measure.

This could be responded to by pointing out that the reintroduction of wolves boosts biodiversity because, when they kill other animals, scavengers have more food, which allows them to reproduce themselves and multiply. This is so in particular in the case of insects. Therefore, this could be something that would increase, rather than decrease, animal wellbeing. The reason would be, simply, that there could be more sentient animals alive (on the question on insect sentiency see Smith 1991). This may seem a reasonable 
argument at first sight. However, there are some strong reasons to reject it. I will present them now.

\title{
10. The Question of the Predominance of Suffering over Happiness in Nature
}

\author{
Yew-Kwang Ng (1995) and Alan Dawrst (2007) have claimed \\ that the amount of suffering in nature vastly exceeds the amount of \\ wellbeing. In a nutshell, their argument can be reconstructed as \\ follows. The reproductive strategies which maximize inclusive fitness \\ very commonly entail that many more animals are born than those \\ who survive (for a locus classicus on this see Pianka 1970). The \\ reason is, of course, that the chances that an animal that has just \\ come into existence has of reaching sexual maturity and procreating \\ can be extremely low. This happens in particular in the case of small \\ animals, who may lay hundreds, or even several thousands eggs. It \\ also happens that these animals are, by far, the ones that exist in the \\ highest numbers in nature. This means that the majority of the \\ sentient animals that come to existence die very soon after they start \\ to be sentient. Many of them die from starvation. Others are eaten \\ alive by predators or parasites. This means that most of these animals \\ in almost all certainty experience more suffering than positive \\ wellbeing in their lives. In other words, that their lives are not worth \\ living. Given this, the assumption that the conservation of \\ environmental balance is on the overall good for animals appears to \\ be highly questionable. It would be false if we hold an egalitarian, a \\ sufficientarian or a maximin conception of the good. Or if we assume \\ any other view according to which an outcome in which some \\ individuals gets some benefits but some others get harmed cannot be \\ good (as some who hold deontological or virtue ethics approaches \\ may assume). But it would also be wrong even if we set aside any of \\ these normative views and accepted an aggregative and impersonal \\ conception of the good. The reason is that those animals whose lives \\ are not worth living appear to be, by a large amount, the greater part \\ of the sentient animals existing on Earth's biosphere. Given this, \\ those theories that are based on impersonal views of the good (such
}


as utilitarianism) would have to join all the previously mentioned perspectives in their rejection of the present state of affairs as a good one.

Both Ng and Dawrst assume extremely cautious positions as regards the conclusions to be implied from the facts and arguments they present, and just make the claim that more resources should be employed in doing research on the suffering and wellbeing of animals in nature. This is a very conservative conclusion for them to make, in light of their argument. Anyway, according to this conservative conclusion we cannot just assume that the existing balance of the environment is positive for animals. $\mathrm{Ng}(1995,261)$ wonders: "without welfare biological studies, how do we know that the natural equilibrium in the biosphere is desirable[?]" Most of us seem to take for granted that this is just the case without really spending much time thinking about it. But, on reflection, it is clear that Ng's is correct in wondering whether this is so, at least if we accept that what matters is the good of sentient individuals. So the assumption that the current balance of ecosystem is good for animals, that is widely accepted without being really considered in sufficient detail, cannot be considered a warranted one. All this should drive us to consider in a completely different light the question of intervention in nature, not just in the case we are considering here, but also in general.

\section{The Rejection of Holistic and Biocentric Positions}

We have seen that we have reasons to reject those interventions in nature that harm nonhuman animals. This will be resisted by those who support an ethic according to which there are other values in nature that should be protected. Defenders of environmental holism or biocentrism would argue in this way. However, unless we assume a speciesist viewpoint, their positions will be rejected by most of us, as I have pointed out above. With the exception of a tiny minority of more or less consistent environmentalists such as Linkola, most of those who have claimed to defend either biocentrism or environmental holism have in fact combined these views with an anthropocentric speciesist position. Otherwise, they would accept the 
mass killing of humans for the sake of environmental balance. After all, we all know that the way in which humans alter such balance vastly outweighs the way in which any ungulate or other animal does. However, as we have seen, neither Callicott nor, of course, Leopold, held such a view. Neither do theorists such as Paul Taylor (1986) or Gary Varner (2002), who have raised the flag of biocentrism, assume that the value of the life of a human is tantamount to that of nonsentient living beings such as prokaryota (bacteria, archaea) or nonsentient eukaryota (such as protista, fungi or plants). Or, for that matter, that our lives are as valuable as the lives of each of the cells that compose our own bodies.

There is a conception of value that explains this while rejecting speciesism. In light with what I have claimed in section 4, we can defend that those who can be benefited or harmed are those individuals who have the capacity to have positive or negative experiences. A life with no experiences at all would be of no value. In fact, there would be no subject living it. And ecosystems are also entities which are not conscious. Only the individuals who live in them are. Hence, the latter are the only ones to be morally considered, not ecosystems, biocenoses or biotas as such. This being so, we should care about the consequences that interventions in nature have to sentient animals, rather than to nonsentient beings or ecosystems. We may, of course, need to worry about how such interventions can affect the latter, but for indirect reasons concerning the good of sentient beings.

This also drives us to reject a distinction that a number of environmentalists draw between animals who would belong respectively to what are often called in a rather optimistic fashion the "biotic community" and the "mixed community (of humans and domestic nonhuman animals)" (Callicott 1989). This distinction appears to be completely unacceptable from a nonspeciesist viewpoint (which, incidentally, may also find diversionary the use of the term 'community' to name a relation based on aggression). The same principles we may have when it comes to consider those 
nonhuman animals that are exploited by human beings should apply in the case of those living in the wild. There is no sound reason to discriminate against the former, or against the latter. Since both can be positively and negatively affected by their interaction with other beings, the harms they can suffer need to be considered in the very same way.

\section{Changing the Aims of Intervention}

What I have just pointed out has another significant corollary. Thus far I have claimed that interventions that aim at the conservation of a certain environmental balance by harming sentient animals are objectionable. However, nothing from what we have seen entails that there is anything inherently wrong in intervening or avoiding intervention in nature. It is obvious that this need not be the case if we assume an anthropocentric view. But it is important to note that the same would be true if we considered the matter from a nonanthropocentric perspective. We have seen that if we assume a holistic perspective according to which, to put it in line with Leopold's motto, "the integrity, stability, and beauty of the biotic community" would be the locus of value, we would still have reasons to intervene in nature. In fact, reintroductions of wolves may be an example of a policy in line with this. But if we assume a nonspeciesist position according to which the interests of all the sentient beings involved should be considered, we would also have reasons to intervene in the wild. However, such interventions would have to be aimed at reducing, rather than increasing, the harms that nonhuman animals suffer. This would be the case, in particular, in light of the points made by Ng and Dawrst, according to which important interventions in nature would be very desirable from the point of view of nonhuman animals.

We have also seen that the view that the conservation of the environmental balance of ecosystems is something valuable in itself is, in fact, highly questionable. This being so, it seems we can modify the claim presented above. I have argued that when we intervene in the wild we should do so in ways that do not have a negative impact 
on animal wellbeing. However, we can now go a bit further, and claim something more. We also have reasons to intervene in nature when doing so would decrease the harms nonhuman animals suffer. In fact, we would have reasons to do so even if that conflicted with what defenders of biocentrism or environmental holism may regard as valuable, such as environmental complexity or stability, species conservation or aesthetical appreciation of nature. These are currently seen as ideals we should try to further whenever they do not conflict with significant human interests. However, we have seen we have reasons to reject biocentrism, environmental and speciesist thinking. This means that we should not try to further these environmental ideals either if they conflict with the interests of nonhuman animals. This gives us clear reasons against trying to introduce an ecology of fear into Scotland, or into other places in which this measure is being discussed. But it also gives us strong reasons to consider other ways in which we could intervene in nature in order to minimize animals' suffering and death.

\section{Summary and Conclusion}

In this paper I have argued that (i) intervention is not inherently wrong; (ii) speciesism is unjustified; (iii) the idea that environmental balance is valuable in itself is unwarranted; and (iv) biocentrism must be rejected. What follows from these four claims is that we should change the aims that we are trying to achieve when we intervene in nature. The good of nonhuman animals must be the central concern for that. Regarding the particular case I have examined here, I have not denied that the reintroduction of wolves may be useful to achieve some purposes. Rather, I have defended that the purposes we should aim towards when we intervene in nature are completely different ones, even if this conclusion seems, at first, counterintuitive. We should be wary of our initial intuitions regarding this, given that we have been raised in societies in which nonhuman animals are seldom seriously considered.

The question of the interests of animals living in the wild and the disvalues present in nature has not been properly addressed to date 
(for exceptions see Sapontzis 1984; Olivier 1993; Bonnardel 1996; Cowen 2003; Fink 2005). With regards to this, I want to claim that even if the arguments presented here were wrong, they would at least show that this issue is a very serious one which deserves much more attention than the one it has received so far.

\section{Acknowledgements}

The author, who can be reached at OHorta(a)dilemata.net, thanks Daniel Dorado and Kate Marples for helpful comments. This work has been done with the support of the Spanish Ministry of Science and Innovation (exp. 2008-0423).

\section{References}

Aristotle. 1998. Politics. Oxford: Oxford University Press.

BBC News. 1999. Call for return of Scottish wolves. BBC. http://news.bbc.co.uk/2/hi/sci/tech/ specials/sheffield_99/450318.stm.

--- 2002. Call for wolves to be reintroduced. BBC. http://news.bbc.co.uk/2/hi/uk_news/scotland/2065794.stm.

--- 2008. Call for serious debate on wolf. BBC. http://news.bbc.co.uk/2/hi/uk_news/ scotland/highlands_and_islands/7268765.stm.

Blanco, J. C. 2000, Large carnivore damage in Spain. Carnivore Damage Prevention News 1: 5-6.

Bonnardel, Y. 1996. Contre l'apartheid des espèces: À propos de la prédation et de l'opposition entre écologie et libération animale. Les cahiers antispécistes 14. http://www.cahiersantispecistes.org/article.php3?id_article=103.

Callicott, J. B. 1989. In defense of the land ethic: Essays in environmental philosophy. Albany: State University of New York.

--- 1990. The case against moral pluralism. Environmental Ethics 12: $99-124$.

--- 2000. The land ethic. In A Companion to Environmental Philosophy. 204-217, ed. D. Jamieson, Oxford: Blackwell. 
Carruthers, P. 1992. The animal issue: Moral theory in practice. Cambridge: Cambridge University Press.

Christianson, D. and Creel, S. 2010. A nutritionally mediated risk effect of wolves on elk. Ecology 91: 1184-1191.

Clutton-Brock, T. H., Coulson, T. and Milner, J. M. 2004 Red deer stocks in the Highlands of Scotland. Nature 429: 261-262.

Cowen, T. 2003. Policing nature. Environmental Ethics 25: 169-182.

Creel, S., Winnie, J. A. and Christianson, D. 2009. Glucocorticoid stress hormones and the effect of predation risk on elk reproduction. Proceedings of the National Academy of Sciences 106: 12388-12393.

Dawrst, A. 2009. The predominance of wild-animal suffering over happiness: An open problem. Essays on Reducing Suffering. http://www.utilitarian-essays.com/wild-animals.pdf.

Descartes, R. 1930. Discours de la méthode. Paris: Vrin.

Fink, Ch. K. 2005. The predation argument. Between the Species 5. http://cla.calpoly.edu/bts/issue_05/o5fink.htm.

Hargrove, E. 1992. Foundations of wildlife protection attitudes. In The Animal Rights/ Environmental Ethics Debate: The Environmental Perspective, 151-183, ed. E. C. Hargrove, Albany: State University of New York.

Laundre, J. W., Hernandez, L. and Ripple, W. J. 2010. The landscape of fear: Ecological implications of being afraid. The Open Ecology J ournal 3: 1-7.

Leopold, A. 1966. Sand County almanac, with essays on conservation from Round River. New York: Ballantine Books.

Linkola, P. 2009. Can life prevail?: A radical approach to the environmental crisis. London: Integral Tradition Publishing.

Manning, A. D., Gordon, I. J. and Ripple, W. J. 2009. Restoring landscapes of fear with wolves in the Scottish Highlands. Biological Conservation 142: 2314-2321.

Mech, L. D. 1995. The challenge and opportunity of recovering wolf populations. Conservation Biology 9: 270-278.

Morgan, J. 2007. Crying wolf, now with added bite. The Herald. http://www.theherald.co.uk/search/ display.var.1160642.0.crying_wolf_now_with_added_bite.php. 
Ng, Y.-K. 1995. Towards welfare biology: Evolutionary economics of animal consciousness and suffering. Biology and Philosophy 10: $255-85$.

Nilsen, E. B., Milner-Gulland, E. J., Schofield, L., Mysterud, A., Stenseth, N. C. and Coulson, T. 2007. Wolf reintroduction to Scotland: public attitudes and consequences for red deer management. Proceedings of the Royal Society: Series B, Biological Sciences 274: 995-1002.

Norton, B. G. 1987. Why preserve natural variety? Princeton: Princeton University Press.

Næss, A. 2005. The selected works of Arne Næss. Deep ecology of wisdom, vol. X.Dordrecht: Springer.

O'Connell, S. 2008. Back from the dead: could wolves and wild boar roam Britain again? The Independent. http://www.independent.co.uk/environment/nature/ back-from-the-dead-could-wolves-and-wild-boar-roambritain-again-80690o.html.

Olivier, D. 1993. Pourquoi je ne suis pas écologiste. Les cahiers antispécistes 14. http://www.cahiersantispecistes.org/spip.php?article52

Pianka, E. R. 1970. On r and K selection. American Naturalist 104: 592-597.

Preisser, E. L., Bolnick, D. I. and Benard, M. F. 2005. Scared to death? The effects of intimidation and consumption in predator-prey interactions. Ecology 86: 501-509.

Prugh, L. R., Stoner, Ch. J., Epps, C. W., Bean, W. T., Ripple, W. J., Laliberte, A. S. and Brashares, J. S. 2009. The rise of the mesopredator. Bioscience 59: 779-791.

Reichmann, J. 2000. Evolution, animal 'rights' and the environment. Washington: The Catholic University of America Press.

Ripple, W. J. and Larsen, E. J. 200o. Historic Aspen recruitment, elk, and wolves in Northern Yellowstone National Park, USA. Biological Conservation 95: 361-370.

Ripple, W. J. and Beschta, R. L. 2004. Wolves and the ecology of fear: Can predation risk structure ecosystems? BioScience 54: 123-138. 
Ripple, W. J. and Beschta, R. L. 2007. Restoring Yellowstone's Aspen with wolves. Biological Conservation 138: 514-519.

Sapontzis, S. 1984. Predation. Ethics and animals 5: 27-38.

Scanlon, Th. M. 1998. What we owe to each other. Cambridge: Belknap.

Scottish Government Rural and Environment Research and Analysis Directorate. 2010. Agriculture facts and figures. Edinburgh: Scottish Government Rural and Environment Research and Analysis Directorate, The Scottish Government, http://www.scotland.gov.uk/Resource/Doc/314320/o099836.pdf.

Shelton, J.-A. 2004. Killing animals that don't fit in: Moral dimensions of habitat restoration. Between the Species 4: 121, http://cla.calpoly.edu/bts/issue_04/o4shelton.htm.

Smith, D. W. 2005. Ten years of Yellowstone wolves, 1995-2005. Yellowstone Science 13: 7-33.

Smith, D. W., Stahler, D. R., Albers, E., Metz, M., Williamson, L., Ehlers, N., Cassidy, K., Irving, J., Raymond, R., Almberg, E. and McIntyre, R. 2009. Yellowstone wolf project: Annual report, 2008. Yellowstone National Park: Yellowstone Center for Resources, National Park Service.

Smith, J. A. 1991. A question of pain in invertebrates. Institute for Laboratory Animal Research J ournal 33: 25-32.

Taylor, P. 1986. Respect for nature. Princeton: Princeton University Press.

Varner, G. 2002. Biocentric individualism. In Environmental ethics: What really matters, what really works, 108-120, ed. D. Schmidtz and E. Willot. Oxford: Oxford University Press.

Watson Featherstone, A. 1997. The wild heart of the Highlands. Ecos 18: 48-61.

Whewell, W. 1852. Lectures on the history of moral philosophy in England. John Parker: London.

White, P. J., Smith, D. W., Duffield, J. W., Jimenez, M., McEneaney, T. and Plumb, G. 2005. Yellowstone after wolves: Environmental impact statement predictions and ten-year appraisals. Yellowstone Science 13: 34-41.

Wilson, C. J. 2004. Could we live with reintroduced large carnivores in the UK? Mammal Review 34: 211-232. 
Yellowstone National Park, National Park Service. 2009. Yellowstone elk. Yellowstone National Park. http://www.nps.gov/yell/naturescience/elk.htm. 